\title{
Sulforaphane inhibits growth and blocks Wnt/ $\beta$-catenin signaling of colorectal cancer cells
}

\author{
Dominic B. Bernkopf ${ }^{1}$, Gabriele Daum ${ }^{1}$, Martina Brückner ${ }^{1}$ and Jürgen Behrens ${ }^{1}$ \\ ${ }^{1}$ Experimental Medicine II, Nikolaus-Fiebiger-Center, Friedrich-Alexander University Erlangen-Nürnberg (FAU), 91054 \\ Erlangen, Germany \\ Correspondence to: Dominic B. Bernkopf, email: dominic.bernkopf@fau.de \\ Keywords: colorectal cancer; $\beta$-catenin; sulforaphane; Wnt signaling; TCF \\ Received: June 06, $2018 \quad$ Accepted: September 06, $2018 \quad$ Published: September 21, 2018 \\ Copyright: Bernkopf et al. This is an open-access article distributed under the terms of the Creative Commons Attribution License \\ 3.0 (CC BY 3.0), which permits unrestricted use, distribution, and reproduction in any medium, provided the original author and \\ source are credited.
}

\section{ABSTRACT}

The naturally occurring isothiocyanate sulforaphane (SFN) from cruciferous vegetables is associated with growth inhibition of various cancer types, including colorectal cancer. Colorectal cancer is most frequently driven by hyperactive Wnt/ $\beta$-catenin signaling. Here, we show that SFN treatment reduced growth of three unrelated colorectal cancer cell lines (SW480, DLD1 and HCT116) via induction of cell death and inhibition of proliferation. Importantly, SFN inhibits Wnt/ $\beta$-catenin signaling in colorectal cancer cells as shown by inhibition of $\beta$-catenin-dependent luciferase reporters and repression of $\beta$-catenin target genes (AXIN2, LGR5). SFN inhibits Wnt signaling downstream of $\beta$-catenin degradation and induces the formation of nuclear $\beta$-catenin structures associated with closed chromatin. Co-expression of the transcription factors LEF1 or TCF4 prevented formation of these structures and rescued inhibition of $\mathrm{Wnt} / \beta$-catenin signaling by SFN. Our findings provide a molecular basis explaining SFN effects in colorectal cancer cells and underline its potential for prevention and therapy of colorectal cancer.

\section{INTRODUCTION}

Colorectal cancer is one of the leading causes for cancer-associated morbidity and mortality in industrialized countries therefore representing a major health issue [1]. The vast majority of colorectal carcinomas are initiated by mutations which activate the $\mathrm{Wnt} / \beta$-catenin signaling pathway [2].

The Wnt/ $\beta$-catenin signaling pathway is an evolutionary conserved pathway involved in regulating embryonic patterning of body axes, stem cell fate and tissue homeostasis [3]. A destruction complex consisting of the tumor suppressor adenomatous polyposis coli (APC), axin, casein kinase $1 \alpha(\mathrm{CK} 1 \alpha)$ and glycogen synthase kinase 3 (GSK3) tightly regulates $\beta$-catenin abundance by inducing phosphorylation of $\beta$-catenin thereby triggering its ubiquitination and proteasomal degradation [4]. Binding of Wnt ligands to pairs of frizzled receptors and low-density lipoprotein receptor-related $5 / 6$ (Lrp5/6) co-receptors leads to dishevelled (Dvl)-mediated inhibition of $\beta$-catenin phosphorylation and consequent stabilization of $\beta$-catenin [5]. In the nucleus, stabilized $\beta$-catenin interacts with T-cell factor (TCF)/ lymphocyte enhancer factor (LEF) transcription factors to induce transcription of its target genes, e.g. LGR5, AXIN2, MYC and CCND1 [6-10].

In more than $90 \%$ of all colorectal carcinomas, degradation of $\beta$-catenin is impaired by e.g. truncating loss of function mutations of APC or stabilizing gain of function mutations of $\beta$-catenin resulting in constant $\beta$-catenin accumulation and uncontrolled $\mathrm{Wnt} / \beta$-catenin signaling activity [2]. Mitogenic $\beta$-catenin target genes like $M Y C$ and $C C N D 1$ initiate cell division and fuel cancer growth.

Sulforaphane (SFN) is a naturally occurring isothiocyanate which is found in cruciferous vegetables such as broccoli [11]. Evidence is growing that SFN can inhibit growth of various cancer types derived from different organs thereby arousing interest to use SFN in anti-cancer therapy [12-14]. Consequently, SFN was 
used in a phase II study in men with recurrent prostate cancer and effort is made to optimize SFN production or to develop novel phosphonate analogs [15-17].

Some studies also showed inhibition of colorectal cancer growth by SFN [18, 19]. However, no common molecular mechanism has been revealed to explain SFN function in colorectal cancer cells. Of note, inhibition of colorectal cancer growth by SFN has not been linked to inhibition of $\mathrm{Wnt} / \beta$-catenin signaling yet, although hyperactive $\mathrm{Wnt} / \beta$-catenin signaling is the major driving force of colorectal cancer.

Here, we show SFN-induced growth inhibition of colorectal cancer cells and reveal that SFN is a potent inhibitor of $\mathrm{Wnt} / \beta$-catenin signaling in colorectal cancer cells. Inhibition of $\mathrm{Wnt} / \beta$-catenin signaling by $\mathrm{SFN}$ occurred downstream of $\beta$-catenin degradation, most likely at the level of $\beta$-catenin-TCF transcription complex formation, explaining why SFN is still active in mutated colorectal cancer cells.

\section{RESULTS}

\section{SFN inhibits growth of colorectal cancer cells}

In this study we want to address whether SFN might inhibit growth of colorectal cancer by inhibiting Wnt/ $\beta$-catenin signaling. As a model system we used two unrelated colorectal cancer cell lines with truncating APC mutations (SW480, DLD1) and one with a stabilizing $\beta$-catenin mutation (HCT116). To determine the effect of SFN on cell growth, SW480, DLD1 and HCT116 cells were treated with different concentrations of SFN $(0,0.5,2.5$ and $5 \mu \mathrm{M})$ for 24,48 or $72 \mathrm{~h}$ within their logarithmic proliferation phase. Afterwards, the number of viable cells was assessed by colorimetric measuring of 3-(4,5-dimethylthiazol-2-yl)-2,5-diphenyltetrazolium bromide (MTT) reduction. Of note, SFN significantly inhibited cell growth in a dose-dependent manner in all three cell lines, with an IC50 of $3.7 \mu \mathrm{M}$ for SW480, 3.5 $\mu \mathrm{M}$ for DLD1 and $3.6 \mu \mathrm{M}$ for HCT116 cells (Figure 1A). After $72 \mathrm{~h}$ of $5 \mu \mathrm{M}$ SFN treatment cell numbers of SW480, DLD1 and HCT116 cells were reduced by about 67,73 and $78 \%$, respectively, as compared to growth of untreated controls (Figure 1A). To validate the MTT assay-based results, we performed colony formation assays. In addition to cell growth, this assay measures the ability of single cells to grow out into colonies, a process required for metastasis formation. Treatment of cells with SFN during colony formation significantly reduced the numbers and sizes of colonies for the cancer cell lines SW480, DLD1 and HCT116 in a dose-dependent manner (Figure 1B, 1C). Moreover, SFN treatment inhibited colony formation of three additional colorectal cancer cell lines (CX-1, SW48 and WiDr) indicating broad responsiveness of colorectal cancer cells to SFN (Supplementary Figure 1). Interestingly, in contrast to colorectal cancer cells which depend on Wnt/ $\beta$-catenin signaling to grow, colony formation of U2OS cells, whose growth is independent of Wnt signaling, was significantly less impaired (Supplementary Figure 1).

Together our experiments show that SFN inhibits growth of colorectal cancer cells. Interestingly, SFN was active at concentrations similar to those achieved by oral SFN uptake in a clinical study [15].

\section{SFN induces cell death and inhibits proliferation of colorectal cancer cells}

Next, we wanted to determine whether reduced cell numbers after SFN treatment were due to induction of cell death by SFN and/or due to SFN-induced inhibition of proliferation.

First, SFN treated colorectal cancer cells were stained with propidium iodide (PI) and Annexin V to label dead and apoptotic cells, respectively. FACSbased measurement of PI and Annexin V staining intensities showed that SFN treatment of SW480 cells for $24 \mathrm{~h}$ significantly increased the percentage of dead (PI-positive) and apoptotic (Annexin V-positive) cells in a dose-dependent manner indicating the induction of cell death by SFN via triggering apoptosis (Figure 2A, 2B, 2D). In DLD1 and HCT116 cells, SFN treatment induced cell death without significantly increasing the rate of apoptotic cells suggesting induction of cell death in an apoptosis-independent way (Figure 2A, 2B, 2D). In these experiments staurosporine was used as positive control showing that cell death as well as apoptosis can be efficiently induced in all three colorectal cancer cell lines (Figure 2C, 2E, Supplementary Figure 2A). FACSbased detection of SFN-induced apoptosis in SW480 cells could be confirmed via microscopic analysis of Annexin $\mathrm{V}$ and ethidium bromide (marks dead cells) stained cells (Supplementary Figure 2B). Moreover, quantification of the sub-G1 cells, which have less than one DNA equivalent due to DNA fragmentation in late apoptosis, showed that SFN treatment increased the fraction of these late-apoptotic cells in SW480 cells (Supplementary Figure 2C). This increase was less pronounced in DLD1 and HCT116 cells in line with the Annexin V staining results (Supplementary Figure 2C). The experiments suggest that SFN might induce cell death differentially in SW480 cells compared to DLD1 and HCT116 cells. However, SFN induced cell death in all three colorectal cancer cell lines.

To directly assess cell proliferation, pulse-trace experiments with carboxyfluorescein succinimidyl ester (CFSE) were performed. After a labeling pulse with CFSE to couple this fluorescent dye to cellular macro molecules, the labelled cells were treated with different SFN concentrations $(0,0.5,2.5$ and $5 \mu \mathrm{M})$ for $72 \mathrm{~h}$ before FACS-based measurement of the remaining CFSE staining intensity. Every cell division reduces the CFSE 
staining intensity by $50 \%$ due to the equal distribution of the labelled macro molecules between both daughter cells. Importantly, the measured CFSE staining intensity after $72 \mathrm{~h}$ was significantly higher in SFN treated cells compared to untreated controls in SW480, DLD1 and HCT116 cells (Figure 3A). Moreover, there was a positive correlation between SFN concentrations and remaining CFSE staining indicating that SFN treatment inhibits cell proliferation in colorectal cancer cells in a dose-dependent manner. Since the CFSE staining is reduced by $50 \%$ with every cell division, the CFSE staining reduction within $72 \mathrm{~h}$ allowed to estimate the number of cell divisions. Of note, treatment with $5 \mu \mathrm{M}$ SFN reduced the number of cell divisions in SW480, DLD1 and HCT116 cells by 57,36 and $35 \%$, respectively (Figure $3 \mathrm{~B}$ ). As a positive control for inhibition of proliferation, cells were grown in medium without serum for $72 \mathrm{~h}$ (Supplementary Figure 3). In the three cell lines, $5 \mu \mathrm{M}$ SFN inhibited proliferation as efficiently (DLD1, HCT116) or even more efficiently (SW480) than withdrawal of serum growth factors (Figure 3B).

Together, our data suggest that SFN reduces numbers of colorectal cancer cells by induction of cell death as well as inhibition of cell proliferation.

\section{SFN inhibits Wnt/ $\beta$-catenin signaling in colorectal cancer cells}

Wnt/ $\beta$-catenin signaling activity is associated with cell survival and well-characterized to induce cell

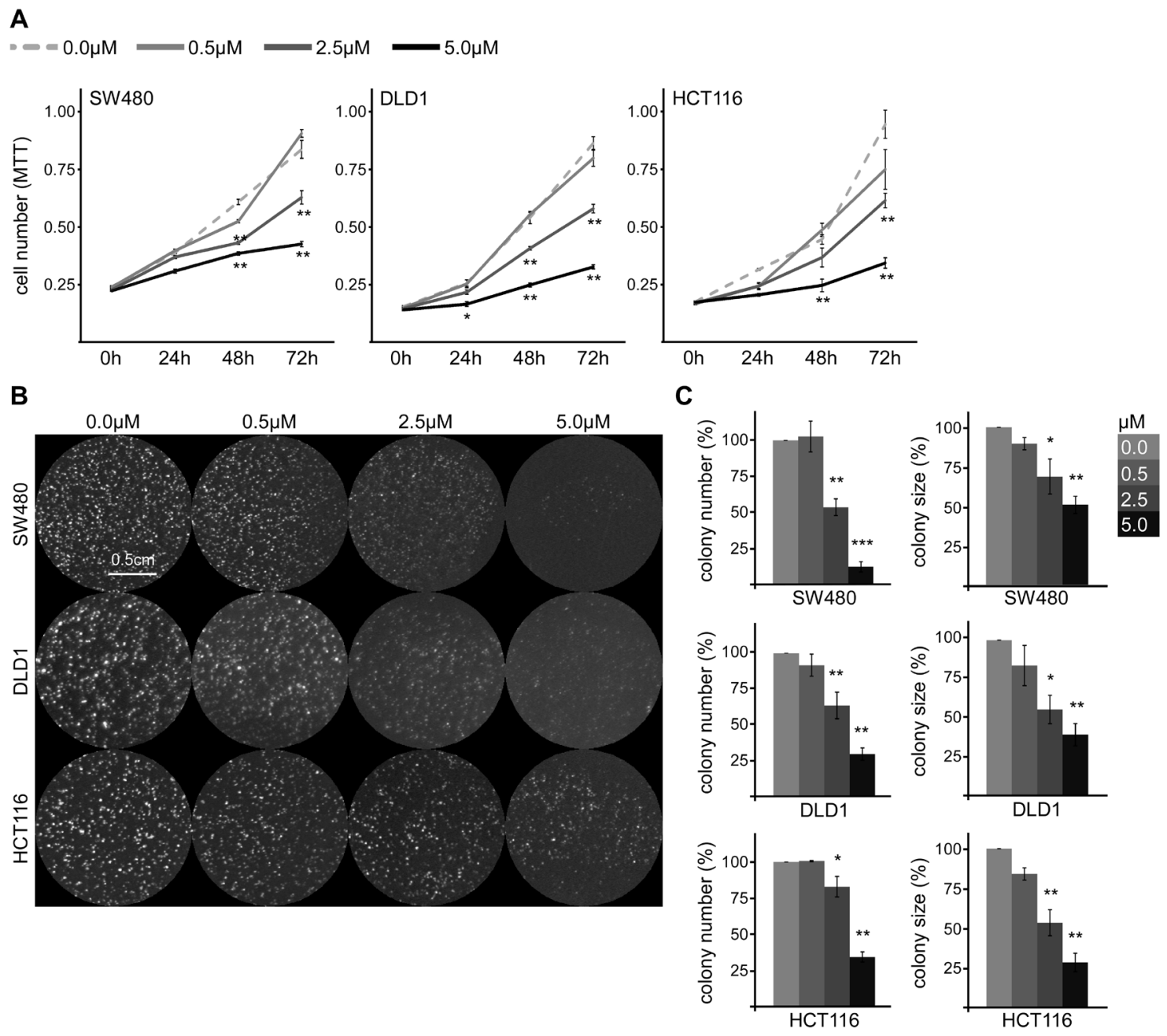

Figure 1: SFN inhibits growth of colorectal cancer cells. (A) Violet MTT color intensity reflecting the number of viable SW480 (left panel), DLD1 (middle panel) or HCT116 cells (right panel) one day after seeding $(0 \mathrm{~h})$ or after $24 \mathrm{~h}, 48 \mathrm{~h}$ and $72 \mathrm{~h}$ of treatment with indicated SFN concentrations. One out of three representative experiments is shown. Results are mean $+/$ - SEM of four replicates ( $\mathrm{n}=4$ ). ${ }^{*} \mathrm{p}<0.05,{ }^{* *} \mathrm{p}<0.01$ (ANOVA followed by post hoc Tuckey test). (B) Cell colonies grown for $96 \mathrm{~h}$ from individual SW480, DLD1, or HCT116 cells in the presence of indicated SFN concentrations. Cells were stained by ethidium bromide incorporation and visualized with UV light. (C) Automated quantification of colony numbers (left column) and sizes (right column) from four independent experiments as in B. Results are mean $+/$ - SEM $(\mathrm{n}=4) .{ }^{*} \mathrm{p}<0.05,{ }^{* *} \mathrm{p}<0.01,{ }^{* * *} \mathrm{p}<0.001$ (Student's $t$ test). 
proliferation. Therefore, we determined whether SFN inhibits $\mathrm{Wnt} / \beta$-catenin signaling to reduce proliferation of colorectal cancer cells. Wnt/ $\beta$-catenin signaling activity was measured by the $\beta$-catenin-dependent TCF optimal (TOP)-FLASH luciferase reporter normalized to the Far from optimal (FOP) control reporter. Importantly, SFN treatment for $24 \mathrm{~h}$ significantly reduced the TOP-FLASH reporter activity in SW480, DLD1 and HCT116 cells in a dose-dependent manner (Figure 4A). Inhibition of Wnt/ $\beta$ catenin signaling by SFN also correlated with the time of

A

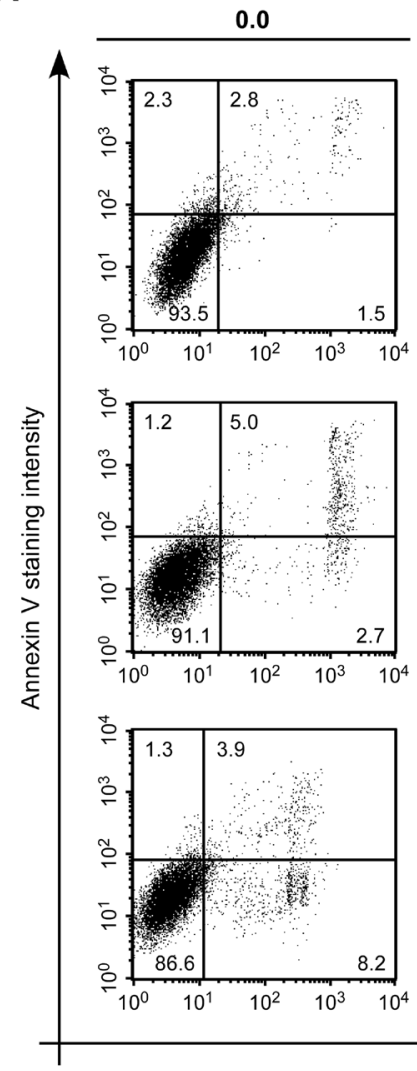

B

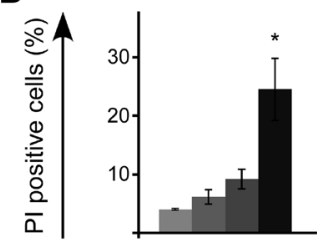

SW480

D

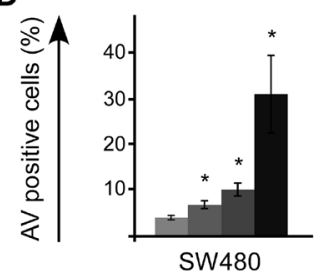

0.5
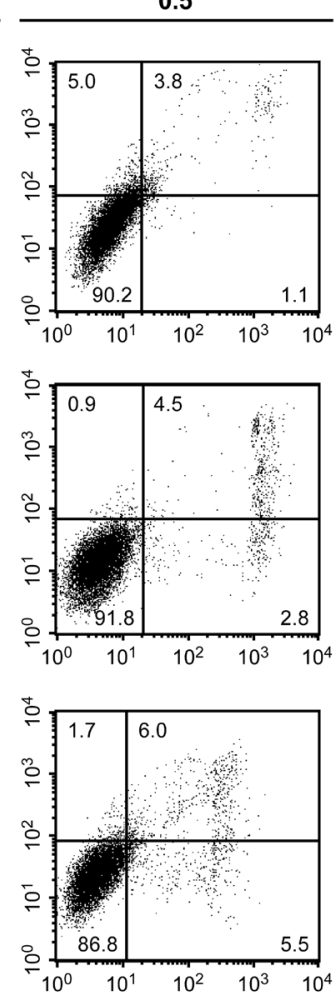

2.5
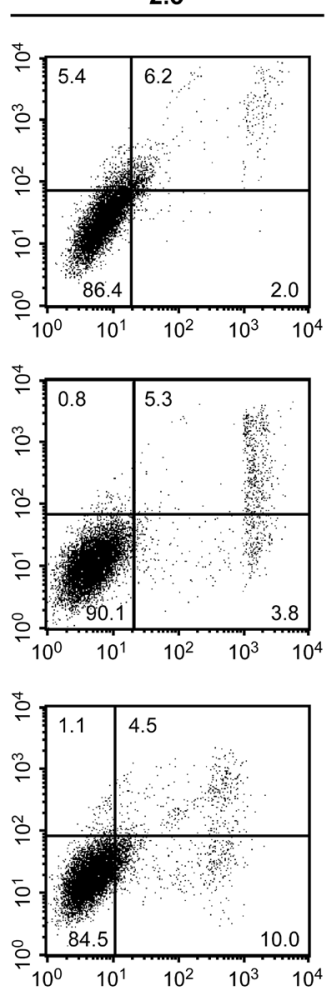

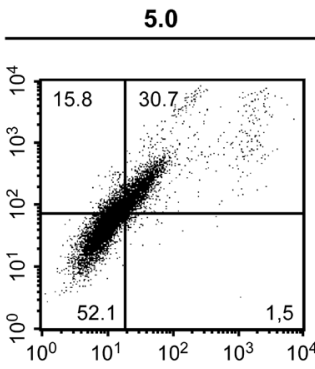

SW480

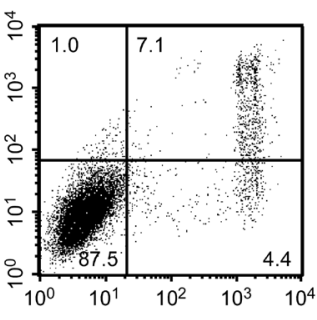

DLD1

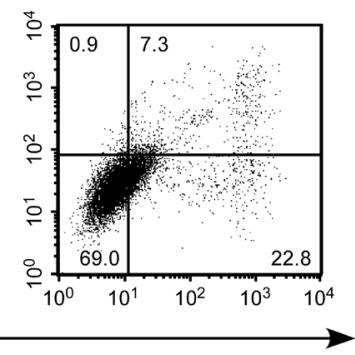

$\mathrm{PI}$ staining intensity

C

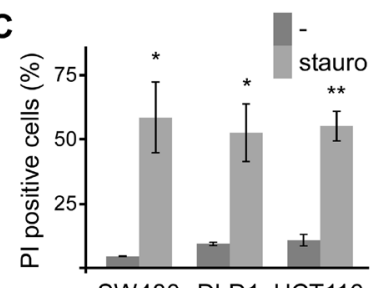

SW480 DLD1 HCT116

E

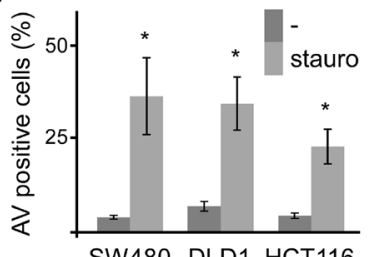

Figure 2: SFN induces death of colorectal cancer cells. (A) FACS-based measurement of Annexin V (y-axis) and propidium iodide (PI, x-axis) staining intensity of SW480, DLD1 and HCT116 cells which were treated for $24 \mathrm{~h}$ with $0,0.5,2.5$ and $5 \mu \mathrm{M}$ SFN, as indicated. Numbers within individual quadrants present the percentages of cells. (B, D) Quantification of (B) propidium iodide (PI) positive cells (upper right and lower right quadrants) and (D) Annexin V (AV) positive cells (upper left and upper right quadrants) of four independent experiments as shown in (A). (C, E) Quantification of (C) propidium iodide (PI) positive cells (upper right and lower right quadrants) and (E) Annexin V (AV) positive cells (upper left and upper right quadrants) without and with staurosporine treatment of SW480, DLD1 and HCT116 cells, of four independent experiments as shown in Supplementary Figure 2A. Results are mean $+/-\mathrm{SEM}(\mathrm{n}=4) .{ }^{*} \mathrm{p}<0.05,{ }^{* *} \mathrm{p}<0.01$ (Student's $t$ test). 
treatment as shown by stronger inhibition up to $70 \%$ after prolonged treatment (48 h, Figure 4A). SFN treatment did not affect the activity of a $\beta$-catenin-independent luciferase reporter (pGL3-Basic) demonstrating specific inhibition of $\beta$-catenin-dependent transcription by SFN (Figure 4B). Moreover, SFN treatment significantly reduced the mRNA expression of the bona fide $\beta$-catenin target genes AXIN2 and LGR5 in SW480 and HCT116 cells (Figure 4C) $[7,8]$. In DLD1 cells, only AXIN2 expression was significantly reduced (Figure 4C). LGR5 expression might be co-stimulated independently of $\beta$-catenin in this cell line. These experiments characterize SFN as a potent inhibitor of $\mathrm{Wnt} / \beta$-catenin signaling in colorectal cancer cells.
A

$$
-0.0 \mu \mathrm{M} \quad-0.5 \mu \mathrm{M} \quad-2.5 \mu \mathrm{M} \quad-5.0 \mu \mathrm{M}
$$
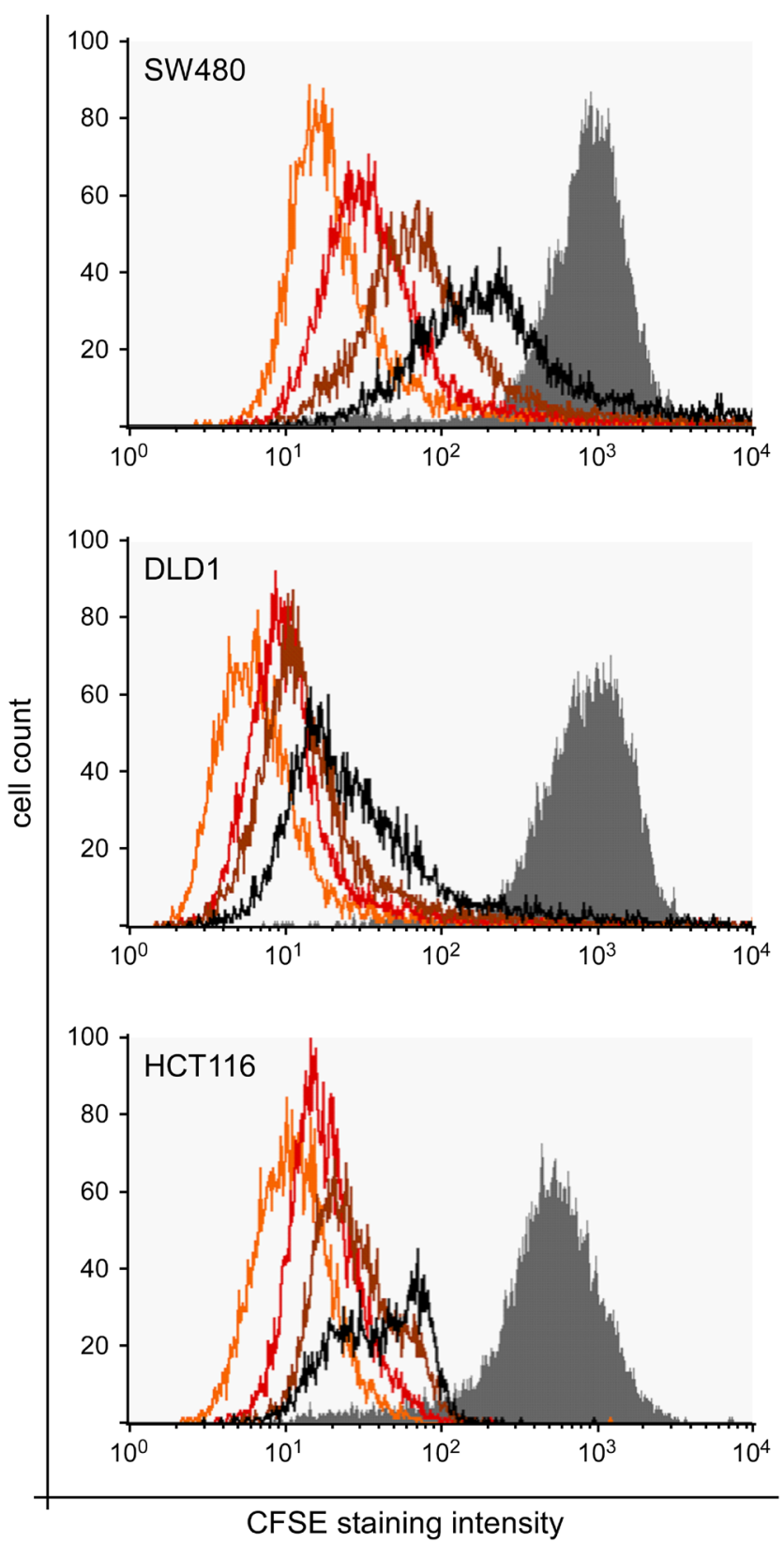

B
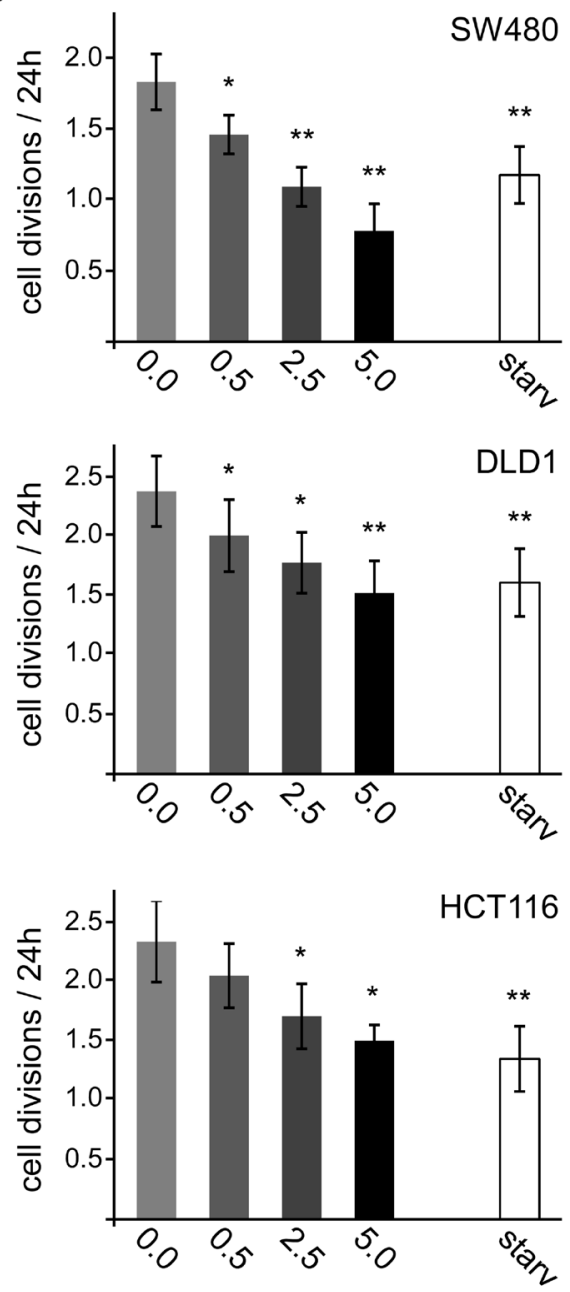

Figure 3: SFN inhibits proliferation of colorectal cancer cells. (A) FACS-based measurement of CFSE staining intensity in SW480, DLD1 and HCT116 cells directly after the CFSE labeling pulse (grey filled) and after $72 \mathrm{~h}$ of treatment with indicated SFN concentrations (unfilled lines). (B) Calculated number of cell divisions per $24 \mathrm{~h}$ based on four independent CFSE dye dilution experiments as shown in (A). Starvation (starv) from serum withdrawal was used as a positive control for reduced proliferation; respective curves are shown in Supplementary Figure 3. Results are mean $+/$ SEM $(n=4) .{ }^{*} \mathrm{p}<0.05,{ }^{* *} \mathrm{p}<0.01$ (Student's $t$ test). 
A

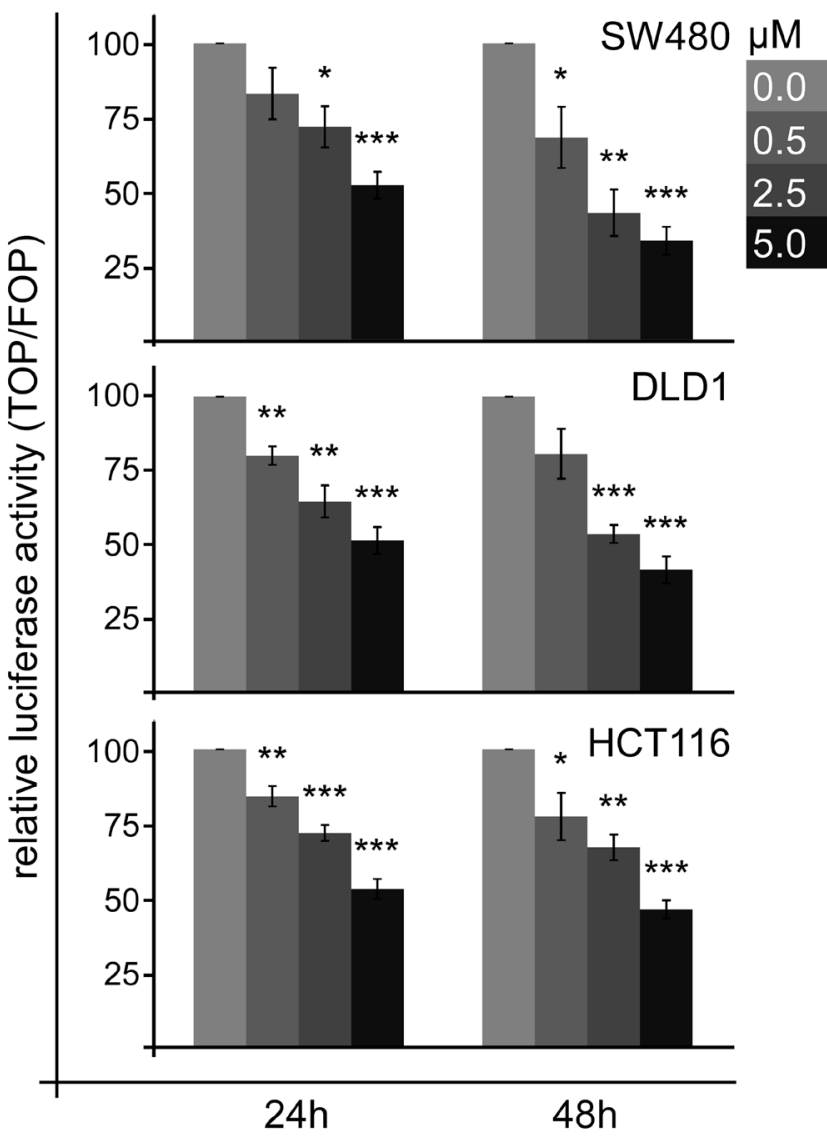

C
B
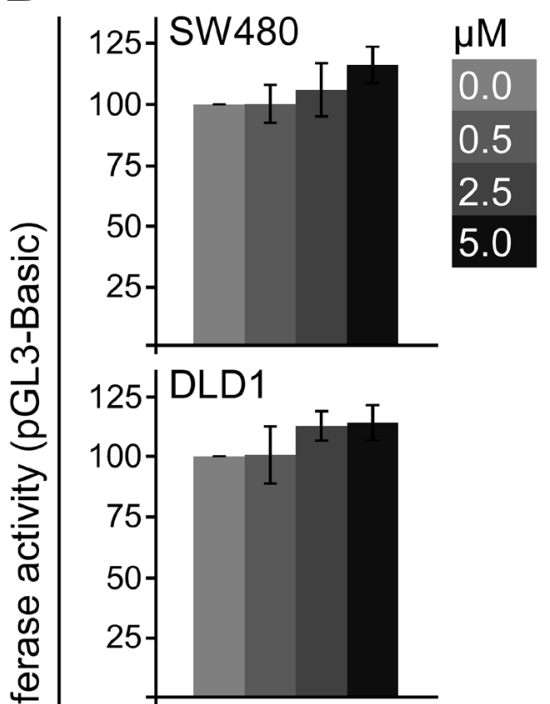

$125+\mathrm{HCT} 116$

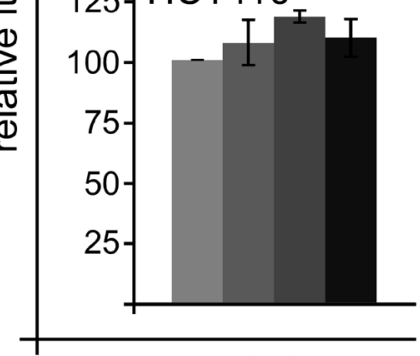

$24 \mathrm{~h}$
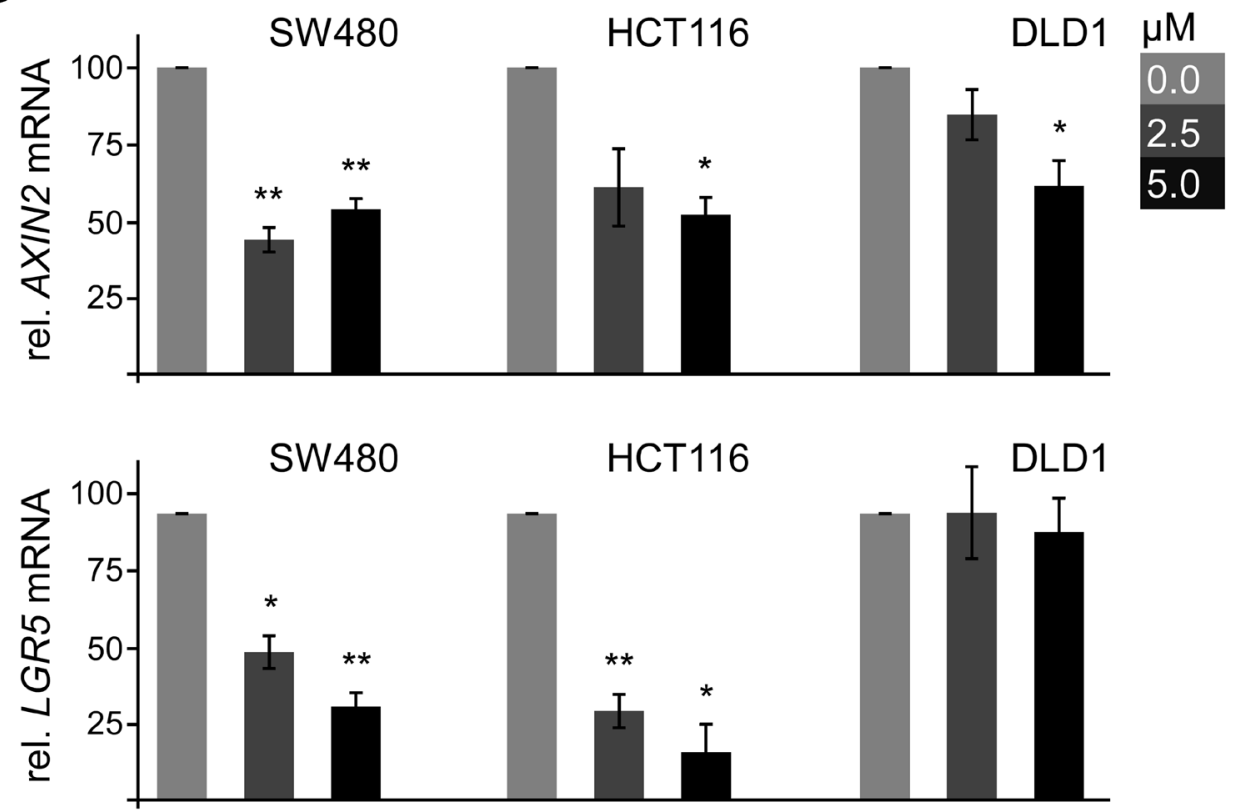

Figure 4: SFN inhibits Wnt/ $\beta$-catenin signaling in colorectal cancer cells. (A) Luciferase activity (TOP/FOP) in SW480, DLD1 and HCT116 cells which were treated with indicated SFN concentrations for $24 \mathrm{~h}$ and $48 \mathrm{~h}$. Results are mean $+/-$ SEM ( $=5$ ). " $\mathrm{p}<0.05$, ${ }^{* *} \mathrm{p}<0.01,{ }^{* * *} \mathrm{p}<0.001$ (Student's $t$ test). (B) Luciferase activity (pGL3-basic, $\beta$-catenin-independent) in SW480, DLD1 and HCT116 cells which were treated with indicated SFN concentrations for $24 \mathrm{~h}$. Results are mean $+/-$ SEM $(\mathrm{n}=3)$. (C) mRNA expression of the $\beta$-catenin target genes AXIN2 (upper panel) and LGR5 (lower panel) normalized to GAPDH in SW480, DLD1 and HCT116 cells which were treated with indicated SFN concentrations for $48 \mathrm{~h}$. Results are mean $+/-\operatorname{SEM}(\mathrm{n}=3) .{ }^{*} \mathrm{p}<0.05,{ }^{* *} \mathrm{p}<0.01$ (Student's $t$ test). 


\section{SFN inhibits Wnt/ $\beta$-catenin signaling downstream of $\beta$-catenin degradation}

In breast cancer cells, SFN was described to inhibit Wnt/ $\beta$-catenin signaling by activating GSK3 [12]. Since $\beta$-catenin phosphorylation in colorectal cancer cells is impaired due to APC truncations or impossible due to $\beta$-catenin mutations, it is unlikely that increased GSK3 activity can be accounted for inhibition of $\mathrm{Wnt} / \beta$-catenin signaling by $\mathrm{SFN}$ in SW480, DLD1 and HCT116 cells. However, to formally exclude this mechanism in colorectal cancer cells we determined whether SFN treatment reduces the inhibiting phosphorylation of GSK3 $\beta$ at serine 9, as described for breast cancer cells [12]. Western blot analysis revealed that phosphorylation of GSK3 $\beta$ at serine 9 was not reduced but rather increased upon SFN treatment in colorectal cancer cells (Supplementary Figure 4A-4C). To reveal other mechanisms for $\mathrm{Wnt} / \beta$-catenin signaling inhibition by SFN we started to pinpoint at which level of the Wnt/ $\beta$-catenin signaling cascade SFN interferes (Figure 5J). For this, we used various stimuli to activate Wnt/ $\beta$-catenin signaling in HEK293T cells transfected with the TOP-FLASH reporter and analyzed whether signaling activity could be blocked by SFN. Although the Wnt/B-catenin activity in unstimulated HEK293T cells is rather low, it was significantly reduced by SFN demonstrating functionality of SFN in HEK293T cells (Figure 5A). Activation of Wnt signaling at the receptor level by Wnt3a conditioned medium or transfection of a constitutively active Lrp6 co-receptor mutant (caLrp6) was efficiently counteracted by SFN treatment (Figure 5B, 5C, 5J). Likewise, activation of the pathway by transient Dvl2 expression, a positive regulator involved in signal transduction from the receptors to the $\beta$-catenin destruction complex, was blocked by SFN (Figure 5D, $5 \mathrm{~J})$. Also, Wnt $/ \beta$-catenin signaling activated by direct inhibition of the $\beta$-catenin destruction complex via siRNA mediated knockdown of APC, which mimics the APC loss of function in SW480 and DLD1 cells, or via the GSK3 inhibitor BIO was prevented by SFN treatment (Figure $5 \mathrm{E}, 5 \mathrm{~F}, 5 \mathrm{~J})$. Finally, even activation of the pathway downstream of the $\beta$-catenin destruction complex by transient expression of a non-degradable $\beta$-catenin mutant (S33Y) was decreased by SFN (Figure 5G, 5J). We verified by Western blotting that SFN treatment did not reduce the levels of transiently expressed caLrp6, Dv12 and $\beta$-catenin S33Y (Supplementary Figure 5A5C). As seen in colorectal cancer cells, SFN did not affect expression of a $\beta$-catenin-independent reporter (pGL3Basic) in HEK293T cells showing specific inhibition of $\beta$-catenin signaling by SFN (Figure $5 \mathrm{H}$ ).

Inhibition of $\mathrm{Wnt} / \beta$-catenin signaling in $\beta$-catenin S33Y expressing HEK293T cells is in line with inhibition of signaling in HCT116 cells which harbor a similar stabilizing $\beta$-catenin mutation. Moreover, SFN was also able to inhibit $\beta$-catenin S33Y-activated Wnt signaling in DLD1 cells indicating that SFN functions by a common mechanism in HEK293T cells and colorectal cancer cells (Figure 5I, Supplementary Figure 5D). Finally, SFN treatment of colorectal cancer cells did not decrease $\beta$-catenin levels in hypotonic cell extracts (Figure $5 \mathrm{~K}$ $5 \mathrm{M})$. Efficient inhibition of $\mathrm{Wnt} / \beta$-catenin signaling in these experiments is shown by the decrease of the $\beta$-catenin target gene Axin 2 in contrast to its constitutively expressed homolog Axin1 (Figure 5K-5M).

\section{SFN induces the formation of inactive $\beta$-catenin- containing transcription complexes}

Together, these experiments suggest that SFN inhibits Wnt $/ \beta$-catenin signaling downstream of $\beta$-catenin degradation at the level of nuclear import or activation of target genes in the nucleus. To investigate this further, the nuclear localization of $\beta$-catenin after SFN treatment was assessed. Transiently expressed $\beta$-catenin is localized diffusely throughout the cytoplasm and the nucleus, and sporadically forms nuclear puncta in a low percentage of cells. Importantly, SFN treatment significantly increased the percentage of cells showing these $\beta$-catenin puncta as well as the size of these puncta in different cell lines (Figure 6A, 6B, 6F, 6G). These puncta were reminiscent of previously described nuclear $\beta$-catenin puncta which have been linked to inhibition of Wnt/ $\beta$-catenin signaling and are enriched for the transcriptional repressor Protein arginine N-methyltransferase 5 (PRMT5) [20, 21]. Therefore, we performed co-staining for PRMT5. Indeed, in some cells with nuclear $\beta$-catenin puncta we observed partial, but clear co-localization of $\beta$-catenin and endogenous PRMT5 in these puncta (Figure 6C). Co-localization with the transcriptional repressor PRMT5 suggests that these nuclear $\beta$-catenin accumulations are transcriptionally inactive and composition-wise similar to those described previously [20].

Upon co-expression of the transcription factor LEF1, which is known to associate with $\beta$-catenin to activate $\beta$-catenin-dependent transcription, $\beta$-catenin was completely recruited into the nucleus, as previously reported (Figure 6D, 6E) [6]. Of note, SFN failed to induce the formation of $\beta$-catenin puncta in the presence of LEF1 (Figure 6D-6G). In line, co-expression of LEF1 or TCF4, another member of the TCF/LEF transcription factor family, together with $\beta$-catenin S33Y largely rescued the inhibition of $\beta$-catenin-dependent transcription by SFN in luciferase reporter assays (Figure 6H). Also in colorectal cancer cells, transient expression of TCF4 significantly rescued SFN-induced inhibition of Wnt/ $\beta$ catenin signaling (Figure 6I). Our results suggest that SFN inhibits $\mathrm{Wnt} / \beta$-catenin signaling by inducing the formation of nuclear $\beta$-catenin puncta which might represent inactive or even repressive $\beta$-catenin containing transcription complexes (see Discussion). 


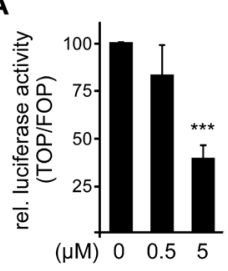

D

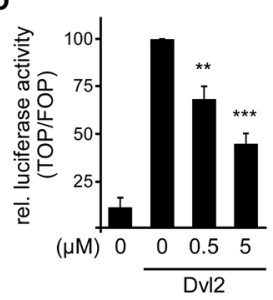

G

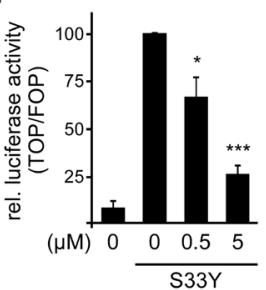

K

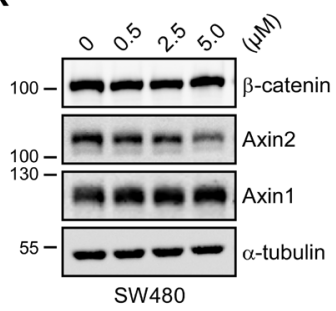

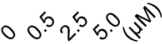
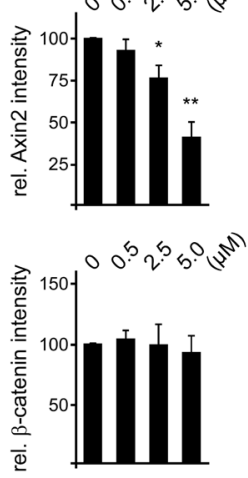

B

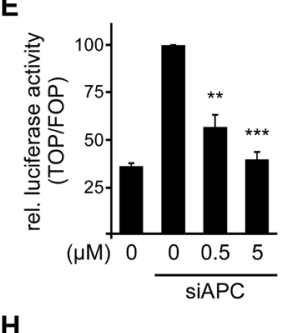

H

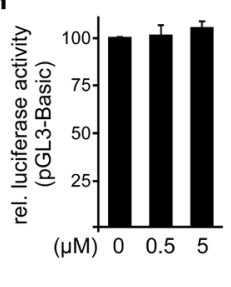

L

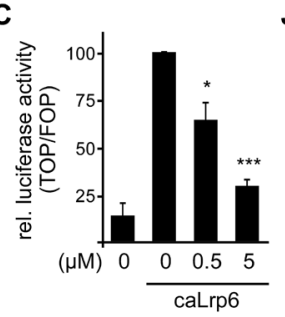

F

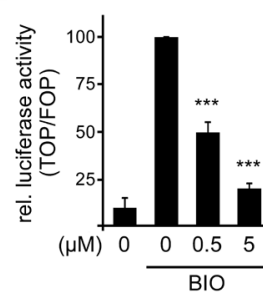

I

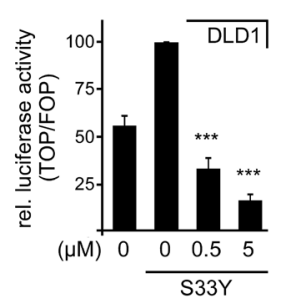

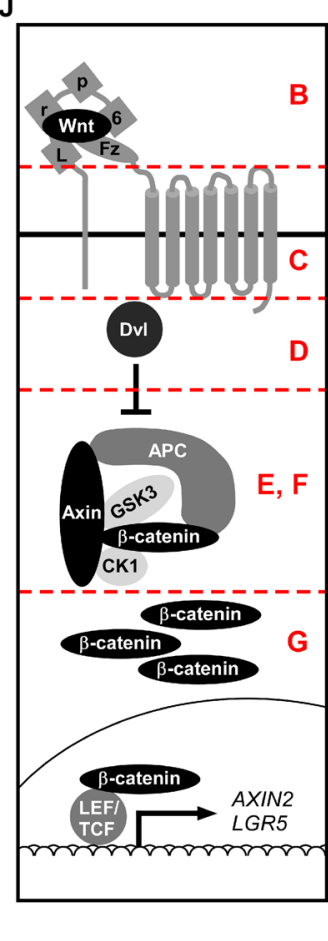

M
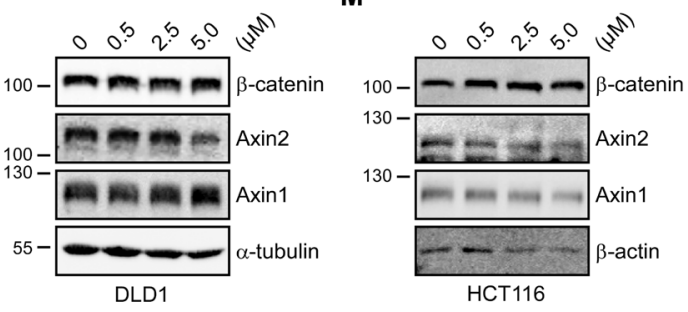

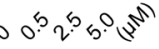

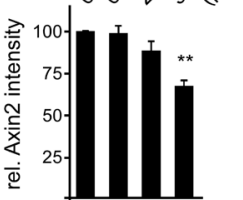

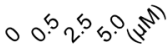
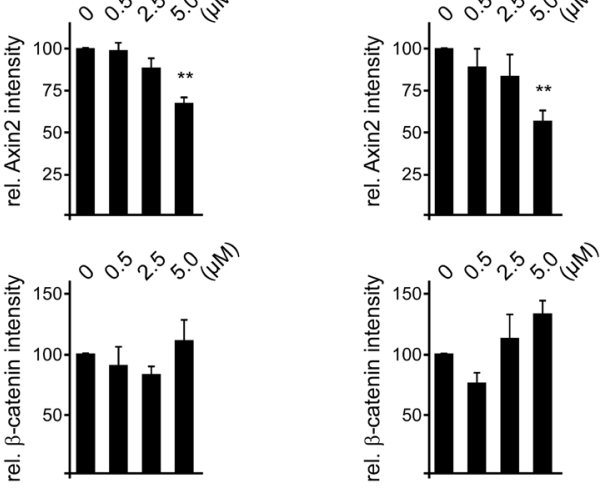

Figure 5: SFN inhibits Wnt/ $\boldsymbol{\beta}$-catenin signaling downstream of $\boldsymbol{\beta}$-catenin degradation. (A-G) Luciferase activity (TOP/FOP) after $24 \mathrm{~h}$ treatment with indicated SFN concentrations $(0,0.5,5 \mu \mathrm{M})$ in HEK293T cells with basal Wnt signaling activity (A) or stimulated Wnt signaling activity by Wnt3a conditioned medium (B), transient expression of constitutively active Lrp6 (C) or Dvl2 (D), knockdown of APC (E), GSK3 inhibition via BIO (F) or transient expression of the stabilized $\beta$-catenin mutant S33Y (G). (H) Luciferase activity (pGL3basic, $\beta$-catenin-independent) in HEK293T cells which were treated with indicated SFN concentrations for $24 \mathrm{~h}$. (I) Luciferase activity (TOP/FOP) in DLD1 cells transiently expressing the stabilized $\beta$-catenin mutant S33Y, after treatment with indicated SFN concentrations for $24 \mathrm{~h}$. Results are mean $+/-\operatorname{SEM}(\mathrm{n}=5) .{ }^{*} \mathrm{p}<0.05,{ }^{* *} \mathrm{p}<0.01,{ }^{* * *} \mathrm{p}<0.001$ (Student's $t$ test). (J) Schematic illustration of the Wnt/ $\beta$-catenin signaling cascade. Positions of pathway activation in (B to $\mathbf{G})$ are indicated in red. (K-M) Upper panels: Western blotting for indicated proteins in hypotonic lysates of SW480 (K), DLD1 (L) and HCT116 (M) cells which were treated for $24 \mathrm{~h}$ with SFN concentrations indicated above the blots. Middle panels: 2D densitometry quantification of Axin2 levels ( $\beta$-catenin target gene) which were normalized to the expression of Axin1 (constitutively expressed Axin2 homolog) from four independent experiments as shown in the upper panels. Lower panels: $2 \mathrm{D}$ densitometry quantification of $\beta$-catenin levels which were normalized to the loading control ( $\alpha$-tubulin/ $\beta$-actin) from four independent experiments as shown in the upper panels. Results are mean $+/-\operatorname{SEM}(\mathrm{n}=4) .{ }^{*} \mathrm{p}<0.05,{ }^{* *} \mathrm{p}<0.01$ (Student's $t$ test). 
A

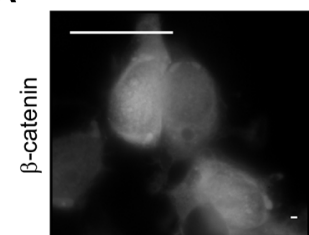

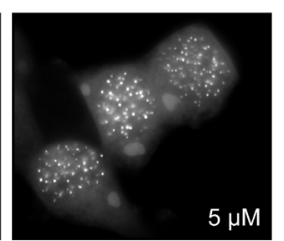

HEK293T

c

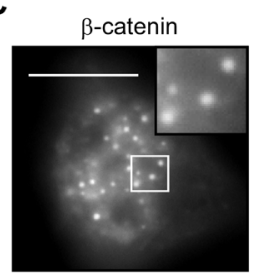

D
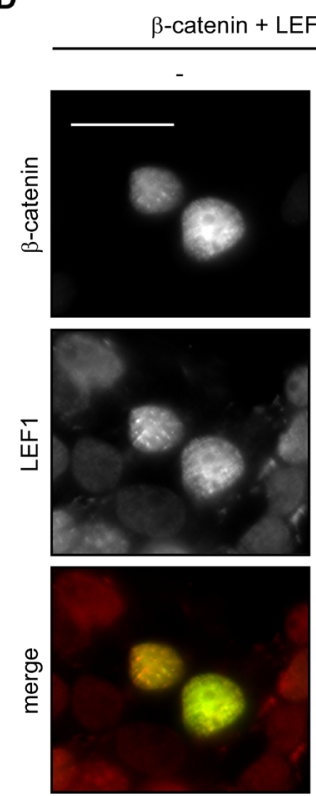

H
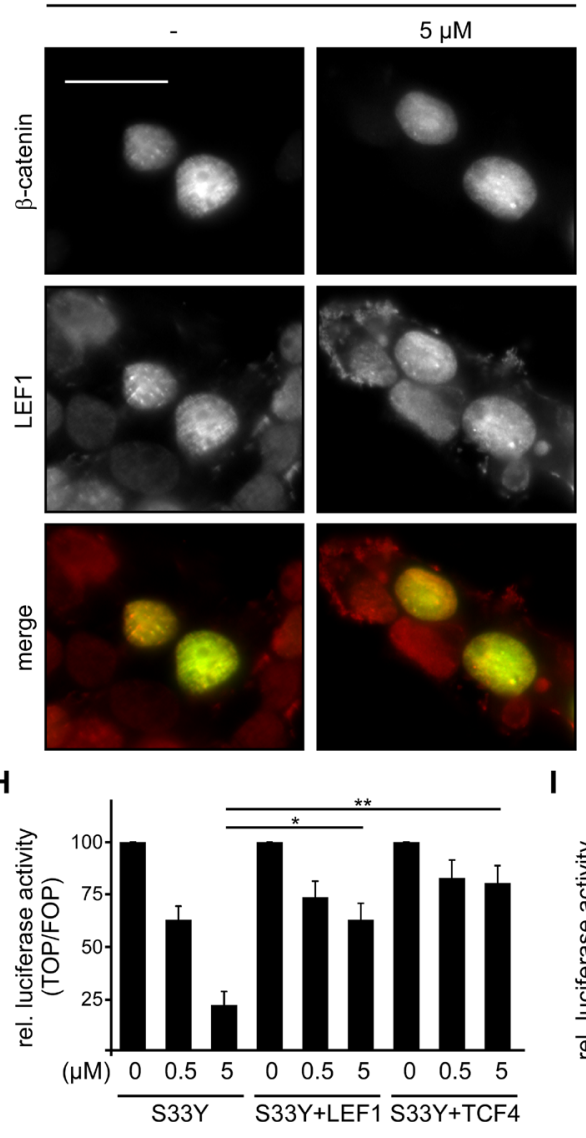

I
B
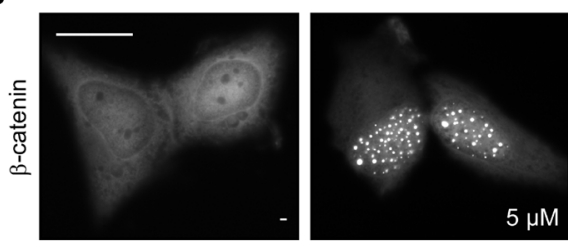

U2OS

F

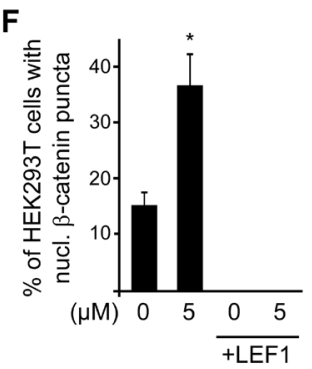

G

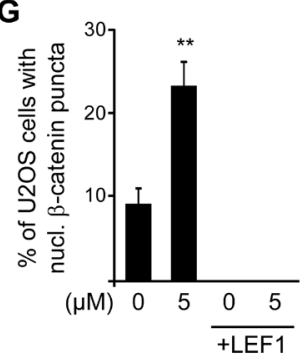

$\mathbf{E}$

$\beta$-catenin + LEF1 (in U2OS)
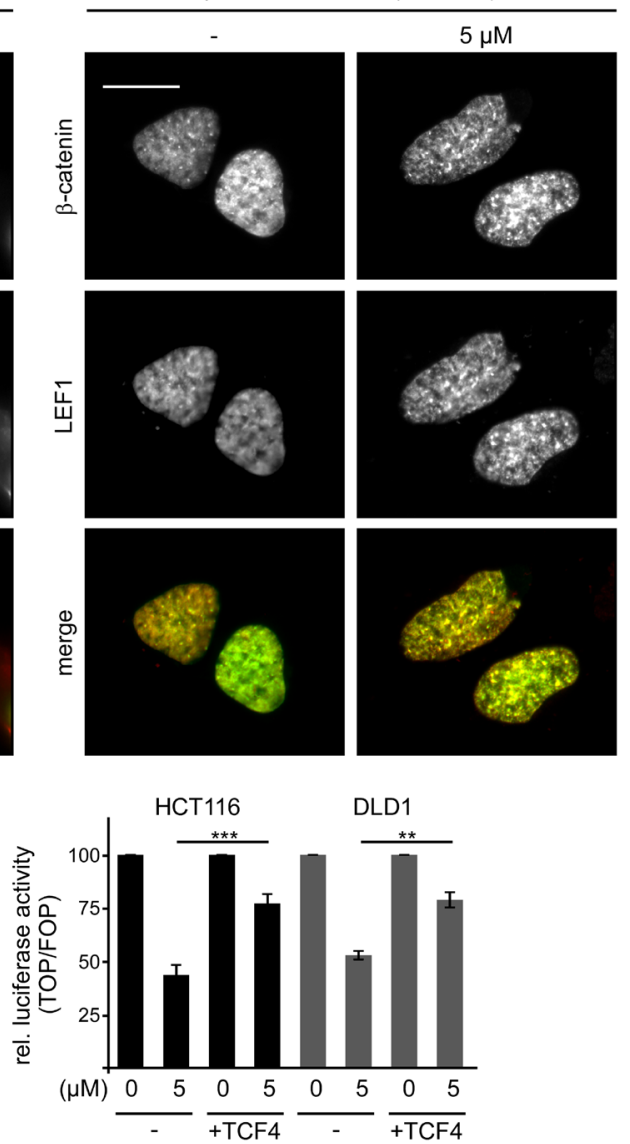

Figure 6: SFN induces the formation of inactive $\beta$-catenin-containing transcription complexes. (A and B) GFP- $\beta$-catenin fluorescence in transfected HEK293T (A) and U2OS cells (B) which were left untreated (-) or treated with $5 \mu \mathrm{M} \mathrm{SFN}$ for $24 \mathrm{~h}$. Scale bar: $20 \mu \mathrm{m}$. (C) Immunofluorescence staining for PRMT5 (red) in GFP- $\beta$-catenin (green) transfected HEK293T cells which were treated with $5 \mu \mathrm{M} \mathrm{SFN}$ for $24 \mathrm{~h}$. Scale bar: $10 \mu \mathrm{m}$. Insets are magnified in the top right corner. (D and E) GFP- $\beta$-catenin fluorescence (green) and immunofluorescence staining for HA-LEF1 (red) in co-transfected HEK293T (D) and U2OS cells (E). Cells were left untreated (-) or treated with $5 \mu \mathrm{M}$ SFN for $24 \mathrm{~h}$. Scale bar: $20 \mu \mathrm{m}$. (F and $\mathbf{G}$ ) Quantification of cells with nuclear (nucl.) $\beta$-catenin puncta from experiments as described in (A and $\mathbf{D})(\mathbf{F})$, and $(\mathbf{B}$ and $\mathbf{E})(\mathbf{G})$. Results are mean $+/$ - SEM $(\mathrm{n}=3)$. ${ }^{*} \mathrm{p}<0.05,{ }^{* *} \mathrm{p}<0.01$ (Student's $t$ test). (H) Luciferase activity (TOP/FOP) after $24 \mathrm{~h}$ treatment with indicated SFN concentrations $(0,0.5,5 \mu \mathrm{M})$ in HEK293T cells transfected with the stabilized $\beta$-catenin mutant S33Y, S33Y + HA-LEF1 or S33Y + CFP-TCF4. Results are mean +/- SEM ( $(\mathrm{n}=5) .{ }^{*} \mathrm{p}<0.05,{ }^{* *} \mathrm{p}<0.01$ (Student's $t$ test). (I) Luciferase activity (TOP/FOP) after $24 \mathrm{~h}$ treatment with indicated SFN concentrations $(0,5 \mu \mathrm{M})$ in HCT116 (black bars) and DLD1 cells (grey bars) without (-) or with co-transfection of CFP-TCF4. Results are mean $+/-\operatorname{SEM}(\mathrm{n}=5) .{ }^{* *} \mathrm{p}<0.01,{ }^{* * *} \mathrm{p}<0.001$ (Student's $t$ test). 


\section{DISCUSSION}

In this study, we characterize SFN as potent inhibitor of $\mathrm{Wnt} / \beta$-catenin signaling in colorectal cancer cells. SFN inhibited $\beta$-catenin-dependent reporter activity and repressed $\beta$-catenin target gene expression in a dose-dependent manner at concentrations which can be achieved in the blood through oral SFN uptake [15]. To our knowledge, this is the first time to show inhibition of $\mathrm{Wnt} / \beta$-catenin signaling by SFN in cells with mutations in components of the $\beta$-catenin destruction complex (APC; SW480, DLD1) or stabilizing mutations of $\beta$-catenin (HCT116). So far, only few studies describe inhibition of Wnt $/ \beta$-catenin signaling by SFN in cells with an intact $\beta$-catenin degradation machinery and the underlying mechanism(s) are poorly understood. Inhibition of Wnt signaling by enhancing GSK3 function, as has been described for SFN in breast cancer cells, is unlikely to be effective in colorectal cancer cells and could not be revealed in our study [12]. In contrast, our data clearly show SFN-induced inhibition of Wnt/ $\beta$-catenin signaling downstream of $\beta$-catenin degradation because (i) SFN treatment did not reduce $\beta$-catenin levels, (ii) SFN inhibited Wnt signaling activated by the stabilized $\beta$-catenin mutant S33Y, (iii) SFN inhibited Wnt signaling in HCT116 cells which harbor a stabilizing $\beta$-catenin mutation similar to the S33Y mutant, and (iv) inhibition of Wnt signaling by SFN could be rescued by LEF1 or TCF4 expression. Inhibition of Wnt/ $\beta$-catenin signaling downstream of $\beta$-catenin degradation explains how SFN can be functional in colorectal cancer cells with impaired $\beta$-catenin degradation.

Mechanistically, SFN, most likely, prevents the formation of active $\beta$-catenin-based transcription complexes in the nucleus. Like ARID1B, a chromatin remodeling factor which inhibits $\mathrm{Wnt} / \beta$-catenin signaling, SFN increased the formation of nuclear $\beta$-catenin puncta, which had previously been linked to closed chromatin structures and reduced $\beta$-catenin-dependent transcription [20]. Increasing the levels of activating transcription factors of the TCF/LEF family (LEF1, TCF4) by transient expression rescued the induction of inhibitory $\beta$-catenin puncta as well as the inhibition of $\mathrm{Wnt} / \beta$-catenin signaling by SFN. Possibly, SFN treatment causes clustering of $\beta$-catenin in presumably inactive puncta, and/or induces binding of negative chromatin remodeling factors such as PRMT5 to $\beta$-catenin or other complex components. A nuclear function of SFN, as suggested by our proposed mechanism, is in line with a previous study demonstrating that SFN inhibits NF- $\mathrm{KB}$ signaling in the nucleus downstream of I $\mathrm{B}$ [22].

The $W n t / \beta$-catenin signaling pathway is known to promote cell survival and to stimulate cell proliferation. In line, after inhibition of Wnt/ $\beta$-catenin signaling by SFN we observed increased cell death and reduced proliferation in all three colorectal cancer cell lines. Although inhibition of
Wnt/ $\beta$-catenin signaling could explain the induction of cell death by SFN [23, 24], there might be contributions via other mechanism(s), like e.g. SFN-induced apoptosis via increased Erk1/2 phosphorylation, which was reported for non-small cell lung cancer cells [25]. Together, increased cell death and reduced proliferation resulted in a dramatic reduction of cell numbers upon SFN treatment in colony formation assays and MTT-based cell growth assays in vitro. The observed growth inhibition of colorectal cancer cells by SFN is in line with previous studies [19]. An early in vivo study showed inhibition of intestinal tumorigenesis by SFN in the $\mathrm{APC}^{\mathrm{MIN}}$ mouse model [18]. The authors excluded inhibition of Wnt/ $\beta$-catenin signaling because $\beta$-catenin levels were not altered [18]. Our data show that SFN in fact inhibits Wnt signaling without altering $\beta$-catenin levels suggesting that inhibition of Wnt signaling could well contribute to the inhibition of intestinal tumorigenesis in vivo.

By revealing SFN-mediated inhibition of Wnt $/ \beta$ catenin signaling in colorectal cancer cells, our study significantly adds to the understanding of how SFN can inhibit colorectal cancer growth. Considering cancer treatment or prevention, it is important to know the mechanistic function of drugs or natural compounds because it helps to predict whether individual tumors will be responsive or not. Since hyperactive Wnt/ $\beta$-catenin signaling represents a hallmark of human colorectal cancerogenesis with more than $90 \%$ of the cancers exhibiting genetic alteration activating the pathway [2], inhibition of Wnt signaling by SFN suggests broad responsiveness of colorectal cancers to SFN treatment and benefits for colorectal cancer prevention through SFN uptake.

\section{MATERIALS AND METHODS}

\section{Cell culture, transfection and small chemicals}

CX-1, DLD1, HCT116, HEK293T, SW48, SW480, U2OS and WiDr cells were grown in DMEM supplemented with $10 \%$ fetal bovine serum (FBS) and penicillin/streptomycin in a $10 \% \mathrm{CO}_{2}$ atmosphere at $37^{\circ} \mathrm{C}$, and subcultured according to ATCC recommendations. DLD1 and SW480 cells were transfected with Lipofectamine2000 (Invitrogen) and HCT116, HEK293T and U2OS cells with polyethylenimine, according to manufacturers' instructions. Wnt3a-conditioned medium was prepared as described previously [26]. SFN and BIO were obtained from Sigma-Aldrich.

\section{MTT cell growth assay}

Two thousand cells (DLD1 and HCT116) or 3000 cells (SW480) were seeded per well in 96-well flatbottomed tissue culture plates and grown in the presence of different SFN concentrations for $24 \mathrm{~h}$ to $72 \mathrm{~h}$, as 
indicated in Figure 1A. At the end of every time point, MTT (Sigma-Aldrich) was added at a final concentration of $0.5 \mathrm{mg} / \mathrm{ml}$ and cells were incubated for another $4 \mathrm{~h}$ at $37^{\circ} \mathrm{C}$ to allow MTT cleavage within the living cells. Afterwards, the produced MTT formazan was dissolved by adding $100 \mu \mathrm{l}$ isopropanol with $0.04 \mathrm{~N} \mathrm{HCl}$ per well and the homogenous violet solution was measured with a Spectra MAX 190 (Molecular Devices) at $570 \mathrm{~nm}$ and normalized to the measurement at a reference wavelength of $690 \mathrm{~nm}$. The measured formazan absorbance is directly proportional to the number of living cells. The assay was performed in technical quadruplicates.

\section{Colony formation assay}

For colony formation assays, 2500 CX-1, DLD1, HCT116, SW48, SW480, U2OS or WiDr cells were seeded per well of a 6-well plate and grown in the presence of different SFN concentrations for $96 \mathrm{~h}$. Afterwards, cells were fixed with 3\% PFA for $10 \mathrm{~min}$ at $\mathrm{RT}$, stained with ethidium bromide ( $50 \mu \mathrm{g} / \mathrm{ml}$ in PBS) and visualized in a UV gel documentation system (Herolab). Images were acquired at constant settings. Using the Metamorph analysis software (Carl Zeiss), numbers and sizes of colonies were quantified from these images in an automated fashion by applying a threshold for light objects.

\section{FACS-based measurement of cell death and proliferation}

To assess SFN induced cell death, cells were treated with indicated SFN concentrations for $24 \mathrm{~h}$ or with $1 \mu \mathrm{M}$ staurosporine (Sigma-Aldrich) overnight, collected in FACS buffer (1x PBS with 2\% FBS and 5 mM EDTA) and stained with $5 \mu \mathrm{g} / \mathrm{ml}$ propidium iodide (Sigma-Aldrich) and Annexin V-FITC (BD Bioscience). Red fluorescence intensity (propidium iodide) or green fluorescence intensity (Annexin V-FITC) of 10,000 individual cells was measured at a FACSCalibur (BD Bioscience). Cell debris was excluded from the analysis by gating on forward and side scatter.

For quantification of the apoptotic sub-G1 cells, cells were either left untreated or treated with $5 \mu \mathrm{M}$ SFN for $24 \mathrm{~h}$, collected, fixed in cold $80 \%$ ethanol at $4^{\circ} \mathrm{C}$ and stained with propidium iodide $(5 \mu \mathrm{g} / \mathrm{ml}$ propidium iodide and $0.4 \mathrm{mg} / \mathrm{ml}$ RNase A in PBS). Red fluorescence intensity (propidium iodide) of 10,000 individual cells was measured at a FACSCalibur (BD Bioscience).

To assess cell proliferation, cells were pulse labeled by incubation with $5 \mu \mathrm{M}$ CFSE (Sigma-Aldrich) for 20 min and either directly measured after the pulse or grown for $72 \mathrm{~h}$ in the presence of different SFN concentrations or in serum free medium (starvation). Green fluorescence intensity (CFSE) of 10,000 individual cells was measured at a FACSCalibur (BD Bioscience). Cell debris was excluded from the analysis by gating on forward and side scatter.

\section{Microscopic analysis of cell death}

SW480 cells were treated with $5 \mu \mathrm{M}$ SFN for $48 \mathrm{~h}$ after which attached cells were trypsinized and combined with the floating cells, pelleted by centrifugation ( $300 \mathrm{~g}$, $3 \mathrm{~min}, \mathrm{RT}$ ) and resuspended in staining solution (1x PBS with $5 \mu \mathrm{g} / \mathrm{ml}$ ethidium bromide [Carl Roth] and Annexin V-FITC [BD Bioscience]). After 15 min incubation at RT in the dark, $15 \mu \mathrm{l}$ of the stained cell suspension was pipetted on a microscope slide, covered with a coverslip and immediately analyzed with an Axioplan II microscope system (Carl Zeiss). Images were acquired using MetaMorph analysis software (Carl Zeiss).

\section{Luciferase reporter assay}

As previously described [27], cells were transfected with a luciferase expression plasmid either with a $\beta$-catenin-dependent promoter (TOP) or with a constitutive promoter (FOP), together with a $\beta$-galactosidase expression plasmid. Cells were co-transfected with further expression plasmids of interest or treated with different substances for 24 to $48 \mathrm{~h}$, as stated in the figure legends. Afterwards, the cells were lysed in luciferase assay buffer (25 mM Tris-HCl pH8, 2 mM EDTA, 5\% glycerol, 1\% Triton X-100, $20 \mathrm{mM}$ DTT) and the luciferase activity was measured by the emission of light upon oxidative luciferin decarboxylation with a Centro LB 960 Microplate Luminometer (Berthold technologies). The $\beta$-galactosidase activity was determined as release of yellow orthoNitrophenol upon ortho-Nitrophenyl- $\beta$-galactoside hydrolysis with a Spectra MAX 190 (Molecular Devices). Luciferase activities of TOP and FOP samples were normalized to the respective $\beta$-galactosidase activity to eliminate transfection efficiency-based differences before calculating TOP/FOP ratios. TOP/FOP assays were performed in technical duplicates.

\section{qRT-PCR analysis}

Cells were treated with indicated SFN concentrations for $48 \mathrm{~h}$ before the whole cellular RNA was isolated using the RNeasy mini kit (QIAGEN) according to manufacturer's instructions. cDNA was synthesized with the AffinityScript QPCR cDNA Synthesis Kit (Agilent Technologies). Quantitative PCR for AXIN2 (for: CCTCAGAGCGATGGATTTCGGG; rev: CCAGTTCCTCTCAGCAATCGGC), LGR5 (for: CTTCCAACCTCAGCGTCTTCACC; rev: GTCAGA GCGTTTCCCGCAAGAC) and GAPDH (for: GTCAA GGCTGAGAACGGGAAGC; rev: GGACTCCACG ACGTACTCAGCG) was performed in a CFX96 RealTime System (Bio-Rad) in triplicates. mRNA expression 
of the Wnt $/ \beta$-catenin target genes AXIN2 and LGR5 was normalized to the housekeeping gene $G A P D H$.

\section{Cell lysis and Western blot}

For Western blotting, cells were lysed after 24 $\mathrm{h}$ treatment with indicated SFN concentrations in hypotonic extraction buffer $(20 \mathrm{mM}$ Tris- $\mathrm{HCl} \mathrm{pH} 7.5,1$ mM EDTA, Roche protease inhibitor cocktail) (Figure 5, Supplementary Figure 4) or luciferase assay buffer (Supplementary Figure 5). Proteins were separated according to sizes by SDS-PAGE and transferred to a nitrocellulose membrane, which was probed with primary antibodies: $m \alpha \beta$-catenin (sc-7963) (SantaCruz), $\mathrm{rb} \alpha$ Axin1 (C76H11), rb $\alpha$ Axin2 (76G6), rb $\alpha$ GSK3 $\beta$ (27C10), rb $\alpha$ phospho-GSK3 $\beta$ (D85E12) (CellSignaling), rat $\alpha \alpha$-tubulin (MCA77G) (Serotec), $\mathrm{m} \alpha \beta$-actin (A5441), rb $\alpha$ HA (H6908) (Sigma-Aldrich), m $\alpha$ GFP (11814460001) (Roche), rb $\alpha$ RFP (ab62341) (Abcam). The horseradish peroxidase (HRP) activity of secondary antibodies, goat $\alpha$ mouse-HRP and goat $\alpha$ rabbit-HRP (Jackson ImmunoResearch), was detected with a LAS3000 (FUJIFILM). Intensities of Western blot bands were quantified with AIDA 2D densitometry.

\section{Immunofluorescence}

Cells were treated with SFN concentrations indicated in Figure 6 for $24 \mathrm{~h}$ before immunofluorescence staining was performed as described previously [28]. In short, cells were fixed in $100 \%$ methanol at $-20^{\circ} \mathrm{C}$ or in $3 \%$ PFA at RT (for PRMT5 staining only), permeabilized with $0.5 \%$ Triton $\mathrm{X}-100$ and blocked with medium to prevent unspecific antibody binding. Afterwards, cells were incubated with primary antibodies against indicated proteins (rb $\alpha$ PRMT5, ab31751, Abcam / rb $\alpha$ HA, H6908, Sigma-Aldrich) and fluorochrome-conjugated secondary antibody (goat $\alpha$ rabbit-Cy3, Jackson ImmunoResearch) for $1 \mathrm{~h}$ each. Stained cells were analyzed with an Axioplan II microscope system (Carl Zeiss) and images were acquired using MetaMorph analysis software (Carl Zeiss).

\section{Plasmids and siRNA}

Expression plasmids for HA-Dvl2, RFPcaLrp6, YFP- $\beta$-catenin S33Y, GFP- $\beta$-catenin, HALEF1 and CFP-TCF4, and the siRNA against APC (5'-AAGACGUUGCGAGAAGUUGGA-3') have been described previously [6, 28-31].

\section{Author contributions}

D.B.B. was involved in conception and design, acquisition and interpretation of data, and writing the manuscript. M.B. and G.D. were involved in acquisition of data. J.B. was involved in conception and design, interpretation of data, and writing the manuscript.

\section{CONFLICTS OF INTEREST}

The authors declare that they have no conflicts of interests.

\section{FUNDING}

This study was funded by a grant from the FriedrichAlexander University Erlangen-Nürnberg Interdisciplinary Center for Clinical Research to D.B.B. (J58).

\section{REFERENCES}

1. Fitzmaurice C, Akinyemiju TF, Al Lami FH, Alam T, Alizadeh-Navaei R, Allen C, Alsharif U, Alvis-Guzman $\mathrm{N}$, Amini E, Anderson BO, Aremu O, Artaman A, Asgedom SW, et al, and Global Burden of Disease Cancer Collaboration. Global, Regional, and National Cancer Incidence, Mortality, Years of Life Lost, Years Lived With Disability, and Disability-Adjusted Life-Years for 29 Cancer Groups, 1990 to 2016: A Systematic Analysis for the Global Burden of Disease Study. JAMA Oncol. 2018 Jun 2. https://doi.org/10.1001/jamaoncol.2018.2706. [Epub ahead of print].

2. Cancer Genome Atlas N. Comprehensive molecular characterization of human colon and rectal cancer. Nature. 2012; 487:330-7. https://doi.org/10.1038/nature11252.

3. Clevers H, Nusse R. Wnt/B-catenin signaling and disease. Cell. 2012; 149:1192-205. https://doi.org/10.1016/j. cell.2012.05.012.

4. Stamos JL, Weis WI. The beta-catenin destruction complex. Cold Spring Harb Perspect Biol. 2013; 5:a007898. https:// doi.org/10.1101/cshperspect.a007898.

5. MacDonald BT, He X. Frizzled and LRP5/6 receptors for Wnt/ $\beta$-catenin signaling. Cold Spring Harb Perspect Biol. 2012; 4. https://doi.org/10.1101/cshperspect.a007880.

6. Behrens J, von Kries JP, Kuhl M, Bruhn L, Wedlich D, Grosschedl R, Birchmeier W. Functional interaction of betacatenin with the transcription factor LEF-1. Nature. 1996; 382:638-42.

7. Lustig B, Jerchow B, Sachs M, Weiler S, Pietsch T, Karsten U, van de Wetering M, Clevers H, Schlag PM, Birchmeier W, Behrens J. Negative feedback loop of Wnt signaling through upregulation of conductin/axin2 in colorectal and liver tumors. Mol Cell Biol. 2002; 22:1184-93.

8. Barker N, van Es JH, Kuipers J, Kujala P, van den Born M, Cozijnsen M, Haegebarth A, Korving J, Begthel H, Peters PJ, Clevers H. Identification of stem cells in small intestine and colon by marker gene Lgr5. Nature. 2007; 449:1003-7. https://doi.org/10.1038/nature06196.

9. He TC, Sparks AB, Rago C, Hermeking H, Zawel L, da Costa LT, Morin PJ, Vogelstein B, Kinzler KW. Identification of c-MYC as a target of the APC pathway. Science. 1998; 281:1509-12. 
10. Tetsu O, McCormick F. Beta-catenin regulates expression of cyclin D1 in colon carcinoma cells. Nature. 1999; 398:422-6.

11. Zhang Y, Talalay P, Cho CG, Posner GH. A major inducer of anticarcinogenic protective enzymes from broccoli: isolation and elucidation of structure. Proc Natl Acad Sci U S A. 1992; 89:2399-403.

12. Li Y, Zhang T, Korkaya H, Liu S, Lee HF, Newman B, Yu Y, Clouthier SG, Schwartz SJ, Wicha MS, Sun D. Sulforaphane, a dietary component of broccoli/broccoli sprouts, inhibits breast cancer stem cells. Clin Cancer Res. 2010; 16:2580-90. https://doi.org/10.1158/1078-0432. CCR-09-2937.

13. Juengel E, Maxeiner S, Rutz J, Justin S, Roos F, Khoder W, Tsaur I, Nelson K, Bechstein WO, Haferkamp A, Blaheta RA. Sulforaphane inhibits proliferation and invasive activity of everolimus-resistant kidney cancer cells in vitro. Oncotarget. 2016; 7:85208-19. https://doi.org/10.18632/ oncotarget. 13421.

14. Leone A, Diorio G, Sexton W, Schell M, Alexandrow M, Fahey JW, Kumar NB. Sulforaphane for the chemoprevention of bladder cancer: molecular mechanism targeted approach. Oncotarget. 2017; 8:35412-24. https:// doi.org/10.18632/oncotarget.16015.

15. Alumkal JJ, Slottke R, Schwartzman J, Cherala G, Munar M, Graff JN, Beer TM, Ryan CW, Koop DR, Gibbs A, Gao L, Flamiatos JF, Tucker E, et al. A phase II study of sulforaphane-rich broccoli sprout extracts in men with recurrent prostate cancer. Invest New Drugs. 2015; 33:4809. https://doi.org/10.1007/s10637-014-0189-z.

16. Psurski M, Janczewski L, Switalska M, Gajda A, Goszczynski TM, Oleksyszyn J, Wietrzyk J, Gajda T. Novel phosphonate analogs of sulforaphane: Synthesis, in vitro and in vivo anticancer activity. Eur J Med Chem. 2017; 132:63-80. https://doi.org/10.1016/j.ejmech.2017.03.028.

17. Tian M, Xu X, Hu H, Liu Y, Pan S. Optimisation of enzymatic production of sulforaphane in broccoli sprouts and their total antioxidant activity at different growth and storage days. J Food Sci Technol. 2017; 54:209-18. https:// doi.org/10.1007/s13197-016-2452-0.

18. Hu R, Khor TO, Shen G, Jeong WS, Hebbar V, Chen C, Xu C, Reddy B, Chada K, Kong AN. Cancer chemoprevention of intestinal polyposis in ApcMin/+ mice by sulforaphane, a natural product derived from cruciferous vegetable. Carcinogenesis. 2006; 27:2038-46. https://doi.org/10.1093/ carcin/bg1049.

19. Frydoonfar HR, McGrath DR, Spigelman AD. Sulforaphane inhibits growth of a colon cancer cell line. Colorectal Dis. 2004; 6:28-31.

20. Vasileiou G, Ekici AB, Uebe S, Zweier C, Hoyer J, Engels H, Behrens J, Reis A, Hadjihannas MV. ChromatinRemodeling-Factor ARID1B Represses Wnt/beta-Catenin Signaling. Am J Hum Genet. 2015; 97:445-56. https://doi. org/10.1016/j.ajhg.2015.08.002.
21. Wang L, Pal S, Sif S. Protein arginine methyltransferase 5 suppresses the transcription of the RB family of tumor suppressors in leukemia and lymphoma cells. Mol Cell Biol. 2008; 28:6262-77. https://doi.org/10.1128/MCB.00923-08.

22. Geisel J, Bruck J, Glocova I, Dengler K, Sinnberg T, Rothfuss O, Walter M, Schulze-Osthoff K, Rocken M, Ghoreschi K. Sulforaphane protects from T cell-mediated autoimmune disease by inhibition of IL-23 and IL-12 in dendritic cells. J Immunol. 2014; 192:3530-9. https://doi. org/10.4049/jimmunol.1300556.

23. Chen S, Guttridge DC, You Z, Zhang Z, Fribley A, Mayo MW, Kitajewski J, Wang CY. Wnt-1 signaling inhibits apoptosis by activating beta-catenin/T cell factor-mediated transcription. J Cell Biol. 2001; 152:87-96.

24. Zhang T, Otevrel T, Gao Z, Gao Z, Ehrlich SM, Fields JZ, Boman BM. Evidence that APC regulates survivin expression: a possible mechanism contributing to the stem cell origin of colon cancer. Cancer Res. 2001; 61:8664-7.

25. Geng Y, Zhou Y, Wu S, Hu Y, Lin K, Wang Y, Zheng Z, $\mathrm{Wu}$ W. Sulforaphane Induced Apoptosis via Promotion of Mitochondrial Fusion and ERK1/2-Mediated 26S Proteasome Degradation of Novel Pro-survival Bim and Upregulation of Bax in Human Non-Small Cell Lung Cancer Cells. J Cancer. 2017; 8:2456-70. https://doi. org/10.7150/jca.19383.

26. Willert K, Brown JD, Danenberg E, Duncan AW, Weissman IL, Reya T, Yates JR 3rd, Nusse R. Wnt proteins are lipidmodified and can act as stem cell growth factors. Nature. 2003; 423:448-52. https://doi.org/10.1038/nature01611.

27. Bernkopf DB, Hadjihannas MV, Behrens J. Negativefeedback regulation of the Wnt pathway by conductin/ axin2 involves insensitivity to upstream signalling. J Cell Sci. 2015; 128:33-9. https://doi.org/10.1242/jcs.159145.

28. Bernkopf DB, Jalal K, Bruckner M, Knaup KX, Gentzel M, Schambony A, Behrens J. Pgam5 released from damaged mitochondria induces mitochondrial biogenesis via Wnt signaling. J Cell Biol. 2018; 217:1383-94. https://doi. org/10.1083/jcb.201708191.

29. Rauschenberger V, Bernkopf DB, Krenn S, Jalal K, Heller J, Behrens J, Gentzel M, Schambony A. The phosphatase Pgam5 antagonizes Wnt/beta-Catenin signaling in embryonic anterior-posterior axis patterning. Development. 2017; 144:2234-47. https://doi.org/10.1242/dev.144477.

30. Hadjihannas MV, Bruckner M, Jerchow B, Birchmeier W, Dietmaier W, Behrens J. Aberrant Wnt/beta-catenin signaling can induce chromosomal instability in colon cancer. Proc Natl Acad Sci U S A. 2006; 103:10747-52.

31. Krieghoff E, Behrens J, Mayr B. Nucleo-cytoplasmic distribution of beta-catenin is regulated by retention. J Cell Sci. 2006; 119:1453-63. https://doi.org/10.1242/jcs.02864. 